\title{
Biochemical and molecular effects of yeast extract applications on anthocyanin accumulation in cv. Sangiovese.
}

\author{
Chiara Pastore ${ }^{1}$, Gianluca Allegro ${ }^{1}$, Gabriele Valentini ${ }^{1}$,Emilia Colucci $^{1}$, Fabrizio Battista ${ }^{2}$, and Ilaria Filippetti $^{1 *}$ \\ ${ }^{1}$ Department of Agricultural and Food Sciences DISTAL - University of Bologna, Viale Fanin 44, Bologna, Italy \\ ${ }^{2}$ Lallemand Italia, Via Rossini 14/B 37060 Castel D’Azzano (VR), Italy
}

\begin{abstract}
The effect of biotic and abiotic elicitors on the secondary metabolism in grapevine is gaining a lot of interest, as it has been shown that they can increase the accumulation of phenolic compounds and anthocyanins in particular. The aim of this research was to verify the biochemical and molecular effects of the application of LalVigne ${ }^{\text {TM }}$ MATURE (Lallemand, St. Simon, France), $100 \%$ inactivated natural yeast (Saccharomyces cerevisiae) on the anthocyanin accumulation in potted plants of Sangiovese. In both years, LVM plants did not differ from C in technological ripening at harvest. A significant increase in anthocyanin concentration and the expression of genes involved in their biosynthesis was found in 2016 in LVM grapes compared to C, while in 2017, a year with extremely warm temperatures, the anthocyanins of C and LVM were comparable, despite a slight increase in LVM after the second treatment.
\end{abstract}

\section{Introduction}

In viticulture, one of the main negative effects caused by global warming concerns the shift between technological and phenolic ripening that is increasing in grape berries. For this reason, the accumulation of sugars is no longer related to an adequate concentration and extractability of polyphenolic compounds. Anthocyanin compounds are responsible for the colour of red grapes and are particularly sensitive to thermal increases: it has been highlighted that temperatures above $30{ }^{\circ} \mathrm{C}$ for prolonged periods during ripening can cause a reduction in the accumulation of these compounds, mainly due to a decrease of their synthesis, often associated with greater degradation [1, 2]. Among the several agronomic techniques developed to tackle the negative effects of climate change, the use of elicitors (compounds of different natures such as oligo-polysaccharides, peptides, proteins and lipids, plant hormones and microorganisms) represents a solution of considerable interest. Elicitors are able to induce a physiological response in the plant, including activation of the secondary metabolism and synthesis of phenolic compounds through the release of reactive oxygen species (ROS), which stimulate the secondary metabolism pathways and activate antioxidant mechanisms [3]. Recent studies have shown that some elicitors can modify the composition of different grape varieties: in Tempranillo, the application of methyl jasmonate and yeast extracts led to an increase in the concentration of both anthocyanins and stilbenes [4, 5]; similar effects were found in Merlot and Monastrell [6]. Further positive effects in the use of elicitors have also been observed in relation to the accumulation of aromas

\footnotetext{
Corresponding author: ilaria.filippetti@unibo.it
}

in grapes and wines of the Groppello Gentile cultivars [7], Monastrell [8] and Sangiovese [9].

Natural inactivated yeast $(100 \%$ Saccharomyces cerevisiae) LalVigne ${ }^{\mathrm{TM}}$ MATURE (Lallemand Inc.) treatments confirm an increase in polyphenols, anthocyanins and a higher level of tannin polymerization as well as a decrease in methoxypyrazine concentration in several experiments conducted on different grapevine cultivars (Merlot, Cabernet Sauvignon, Nebbiolo, Syrah, Temprenillo, Gaglioppo, Corvina, Rondinella and Moscato d'Amburgo) in different areas and seasons [4, 10-11].

Despite the growing interest in elicitor application, very few trials, mainly on cell cultures [12], take into account the possible effect that these compounds could have at molecular level, in stimulating the expression of genes involved in the synthesis of secondary metabolites. In this context, the present study aims to verify the biochemical and molecular effects of the application of LalVigne $^{\mathrm{TM}}$ MATURE on the accumulation of anthocyanins in the Sangiovese cultivar.

\section{Material and methods}

\subsection{Experiment set-up, plant material and sample collection}

The trial was conducted over two years (2016 and 2017) on 6 uniform (in shoots and cluster number) potted vines of Sangiovese cv in the Department of Agricultural and Food Sciences (DISTAL) of the University of Bologna (Italy), comparing untreated controls (C) and plants 
treated with LalVigne ${ }^{\text {TM }}$ MATURE (LVM). The product was carefully applied following the company's instructions, at a concentration equivalent to $1 \mathrm{Kg} / \mathrm{ha}$, and distributed on the whole crop and in two moments during ripening: beginning of veraison (A1, 26/07/16 and $19 / 07 / 17)$ and when $70 \%$ of berries were coloured (A2, 03/08/16 and 31/07/17).

Samples of berries were taken from $\mathrm{C}$ and LVM plants just before treatment (T0), 48 hours after the first treatment, 48 hours, one and three weeks after the second treatment and at harvest in order to perform must biochemical evaluation, and HPLC and molecular analyses. Due to the extreme climatic conditions, an extra sampling for anthocyanin analysis was conducted a week before harvest in 2017 .

At harvest, the crop of each individual plant was harvested separately and the number of bunches, yield per vine and cluster weight were recorded. Compactness (according to the 1983 OIV classification) was estimated visually.

\subsection{Must analyses and anthocyanins separation via HPLC.}

At all sampling dates and in both years, 10 berries were collected from each vine for the analysis of ${ }^{\circ} \mathrm{Brix}, \mathrm{pH}$, and titratable acidity. 20 berries per vine also were collected for anthocyanin analysis via HPLC, following the method described in Mattivi et al. [13] and using a Waters 1525 HPLC (Waters, Milford, MA) equipped with a diode array detector (DAD) and a Phenomenex (Castel Maggiore, BO, Italy) reversed-phase column (RP18, $250 \mathrm{~mm} \times 4 \mathrm{~mm}, 5 \mu \mathrm{M}$ ). Anthocyanins were quantified at $520 \mathrm{~nm}$ using an external calibration curve with malvidin-3-glucoside chloride as standard (SigmaAldrich).

\subsection{RNA extraction and quantitative RT-PCR}

On each date, except at harvest, 15-20 berries, according to the phenological stage, were sampled from each vine and RNA extraction was performed on their skins using a Spectrum ${ }^{\mathrm{TM}}$ Plant Total RNA kit (Sigma-Aldrich). All RNA samples were treated with DNase RQ1 (Promega, Madison, USA) and the cDNA was then synthesized from $1 \mu \mathrm{g}$ of total RNA treated with DNase using the Improm-II ${ }^{\mathrm{TM}}$ system (Promega, Madison, USA), according to the manufacturer's instructions. The Real Time analysis was performed with a dilution of cDNA (1:20) to which a master mix was added containing SYBR $^{\circledR}$ Green (Applied Biosystems, Foster City, CA, USA) and the primers of the genes of interest. The PCR reaction was conducted on an ABI PRISM StepOnePlus system (Applied Biosystems, Foster City, CA, USA). Each reaction was performed in 3 technical replicates, using actin [14] and ubiquitin genes as references [15]. The primers for the gene expression analysis were retrieved from the literature: for PAL1 (Phenilalanine ammonia lyase) in Belhadj et al. [16]; DFR (dihydroflavonol reductase); LDOX and UFGT (UDP glucose:flavonoid 3-O-glucosyltransferase) from GotoYamamoto et al. [17]; MYBA1 from Jeong et al. [18]. Amplification efficiency was calculated with the LinRegPCR software and used in the calculation of the MNE (Mean Normalized Expression), as reported in Simon [19].

\subsection{Statistical analysis}

Analysis of variance was performed using the mixed procedure available in SAS v9.0 (SAS Institute, Inc., Cary, NC, USA) and treatment comparisons for all data within each year were analysed using the Tukey test.

\section{Results and discussion}

\subsection{Climatic conditions, technological ripening and analyses at harvest.}

The two years of the trial were very different in terms of climatic conditions (Table 1).

Table 1. Average air temperature and rainfall in 2016 and 2017 seasons.

\begin{tabular}{|c|c|c|c|c|}
\hline & \multicolumn{2}{|c|}{$\begin{array}{c}\text { Average air T } \\
\left({ }^{\circ} \mathrm{C}\right)\end{array}$} & \multicolumn{2}{c|}{$\begin{array}{c}\text { Total rainfall } \\
(\mathrm{mm})\end{array}$} \\
\hline & $\mathbf{2 0 1 6}$ & $\mathbf{2 0 1 7}$ & $\mathbf{2 0 1 6}$ & $\mathbf{2 0 1 7}$ \\
\hline April & 14.6 & 14.1 & 45 & 33.4 \\
\hline May & 17.3 & 18.4 & 72.4 & 55.8 \\
\hline June & 21.7 & 24.5 & 107.0 & 21 \\
\hline July & 25.5 & 25.8 & 27.8 & 8 \\
\hline August & 23.7 & 26.3 & 31.8 & 25.2 \\
\hline September & 21.1 & 18.3 & 33.2 & 117.8 \\
\hline
\end{tabular}

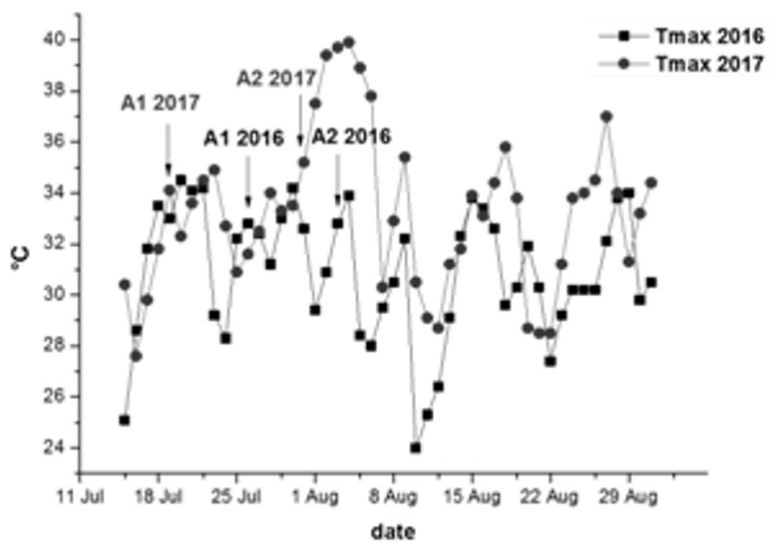

Fig 1. Trend in maximum air temperature from July $15^{\text {th }}$ to August $31^{\text {th }}$ in 2016 and 2017 seasons. Arrows indicate the date on which the two LVM applications were performed in each year. 
The second year of the trial was characterized by higher temperatures, the greatest differences being recorded in June and August, with average air temperature values around $3{ }^{\circ} \mathrm{C}$ higher than the temperature recorded in the same periods in 2016. 2017 was also drier, with total rainfall from April to September being $317.2 \mathrm{~mm}$ in 2016 and $261.2 \mathrm{~mm}$ in 2017 and a near absence during July (Table1). Seasonal differences caused a shift in the onset of ripening, with an advance of around a week in the beginning of veraison in 2017. Furthermore, in the second year, the veraison phase was characterized by extreme high temperatures (Fig. 1).

Despite seasonal diversity, technological ripening proceeded in a similar way in $\mathrm{C}$ and LVM for ${ }^{\circ} \mathrm{Brix}$ (Fig. $2 \mathrm{~A}$ and $2 \mathrm{~B}$ ), titratable acidity and $\mathrm{pH}$ (data not shown), even if a higher concentration of soluble solids was reached in 2017 than in 2016 (Fig. 2).
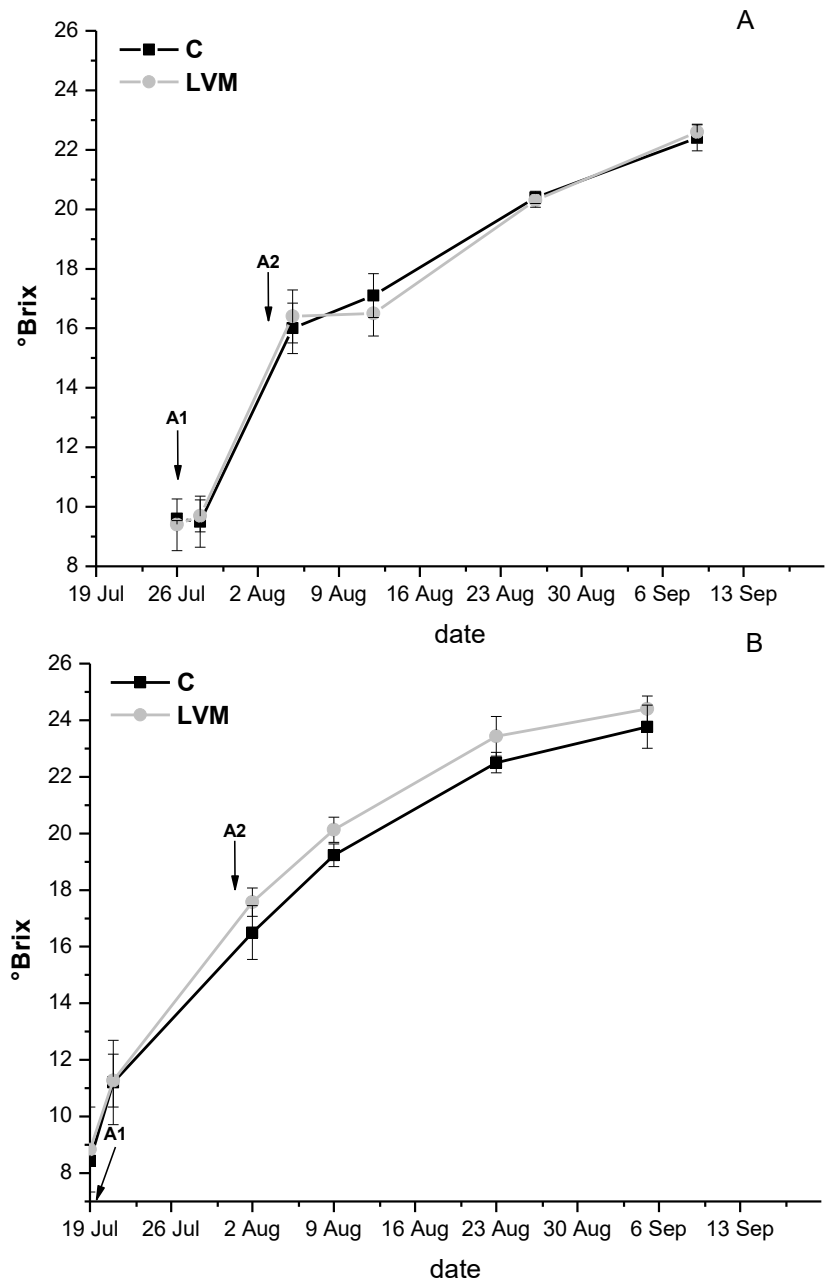

Fig 2. Soluble solids accumulation in $\mathrm{C}$ and LVM berries during 2016 (A) and 2017 (B) seasons. Error bars indicate standard error $(n=3)$.

Furthermore, no differences were detected in either of the two seasons in terms of number of bunches, yield per vine, cluster weight and compactness between $\mathrm{C}$ and LVM (data not shown).

\subsection{Anthocyanin accumulation during ripening and composition at harvest.}

A
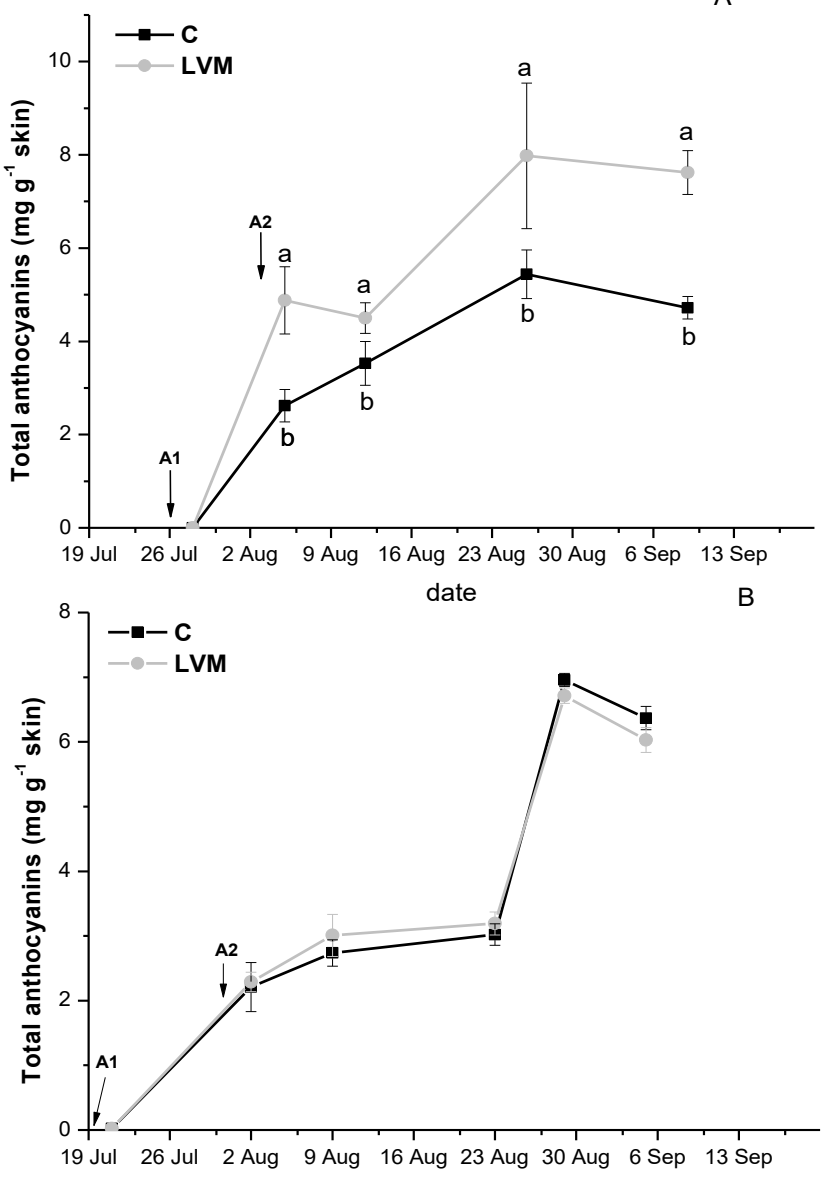

date

Fig 3. Anthocyanin accumulation in C and LVM berries during 2016 (A) and 2017 (B) seasons. Error bars indicate standard error $(n=3)$. Means followed by different letters differ significantly, as calculated by Tukey statistical analysis $(\mathrm{p}<0.05)$.

The first treatment with LVM was performed in both years in correspondence to the beginning of anthocyanin accumulation in berry skin, and a linear increase in anthocyanin concentration in both C and LVM berries was registered immediately after. The treatment with LVM was only effective in increasing anthocyanin accumulation in comparison to $C$ in 2016. Indeed, in that year, following the two LVM applications and until harvest, the anthocyanin concentration was always higher in LVM (Fig. 3A). Conversely, anthocyanin concentration was not affected by LVM treatment in 2017 and during ripening. At harvest C and LVM berries showed overlapping trends of anthocyanin accumulation, even if an increasing, but not statistically different, trend was observed in LVM berries after the second treatment (Fig. 3B).

The treatment with LVM did not affect anthocyanin composition at harvest and C and LVM berries preserved the typical Sangiovese anthocyanin profile (Table 2). 
Table 2. Anthocyanin profile (\%) of C and LVM berries at harvest in 2016 and 2017.

\begin{tabular}{|c|c|c|c|c|c|}
\hline & \multicolumn{5}{|c|}{ 2016 } \\
\hline & $\begin{array}{c}\text { Delph- } \\
\text { 3G }\end{array}$ & $\begin{array}{c}\text { Cyan- } \\
\text { 3G }\end{array}$ & $\begin{array}{c}\text { Pet- } \\
\text { 3G }\end{array}$ & $\begin{array}{c}\text { Peo- } \\
\text { 3G }\end{array}$ & $\begin{array}{c}\text { Malv- } \\
\text { 3G }\end{array}$ \\
\hline C & 14.8 & 28.0 & 14.6 & 13.5 & 29.1 \\
\hline LVM & 13.0 & 31.5 & 12.2 & 17.2 & 26.1 \\
\hline & \multicolumn{5}{|c|}{$\mathbf{2 0 1 7}$} \\
\hline & Delph- & Cyan- & Pet- & Peo- & Malv- \\
& 3G & 3G & 3G & 3G & 3G \\
\hline C & 15.1 & 37.6 & 12.9 & 16.0 & 18.4 \\
\hline LVM & 16.9 & 40.1 & 13.0 & 14.4 & 15.6 \\
\hline
\end{tabular}

\subsection{Gene expression analysis of key genes involved in anthocyanin biosynthesis in grape skin.}

Gene expression analysis was conducted on C and LVM berry skins in the two seasons on all genes involved in flavonoid and anthocyanin biosynthesis, including one PAL isoform, PAL1, which was demonstrated to be involved in grapevine plant response to elicitors [16].

A general expression enhancement of the analysed genes was observed in LVM treated berries only in 2016, when the treatment was effective in increasing anthocyanin accumulation (Fig. 4). PAL1, which controls the first step in phenylpropanoid biosynthesis reached a peak of expression during veraison, after which a rapid decrease was observed in C and LVM in both years. In 2016, the decrease was slowed down by the second application and thereafter an increase of expression was detected in LVM until the end of ripening (Fig. 4A). Contemporarily, an earlier activation of MYBA1 was observed in LVM berries and this was effective in increasing UFGT expression, which was higher in LVM berries in comparison to $\mathrm{C}$ starting from 48 hours after the first LVM application and until 1 week after the second (Fig. 4B and 4C). On the contrary, no differences between $\mathrm{C}$ and LVM were detected during ripening in 2017 in any analysed gene (Fig. 4D-F).

A similar behaviour was observed for DFR and LDOX, involved in the last step of anthocyanin biosynthesis, whose expression was induced in LVM 48 hours after the second application only in 2016 (data not shown).

\section{Discussion}

In the context of climate change, several agronomic practices have been developed for application postveraison, such as trimming or defoliation of the apical part of the shoots, with the purpose of slowing down accumulation of sugars to favour phenolic maturity. Another strategy that could be useful to increase anthocyanin concentration may be the application of elicitors, if they do not interfere with technological ripening. In this two-year research, the inactivated yeast extract LVM was applied on Sangiovese twice during the season to evaluate the possible effects on berry ripening and anthocyanin accumulation, giving us insight into the grapevine's response at a molecular level.

Several studies conducted on grapevines reported that the use of different types of elicitors did not cause any variation in the technological ripening of the berries. In particular, no effects were detected on Syrah, Merlot, Gallioppo, Glera and Pinot Grigio $[15,20]$ treated with yeast extracts, in Tempranillo [5] treated with methyl jasmonates and in Cabernet Sauvignon [21] treated with oligosaccharides deriving from pectin. In agreement with previous results, our data suggest that the application of LVM does not affect berry sugar accumulation, titratable acidity or $\mathrm{pH}$ and that this effect is stable across different climatic seasons, like those of 2016 and 2017.

On the contrary-but well documented by several papers on the effect of environmental conditions on anthocyanin accumulation - the application of LVM was able to induce anthocyanin accumulation only in the year in which veraison occurred with maximum temperatures lower than $35^{\circ} \mathrm{C}$, as verified in 2016 . In this case, the increase in anthocyanin accumulation was well correlated with an induction of some genes involved in the synthesis of common phenylpropanoid precursors or specifically involved in anthocyanin biosynthesis. The occurrence of extreme temperature conditions and the subsequent heatwaves, as in 2017, preserve the possible positive effect linked to the application of the yeast extract.

It has been demonstrated that the exogenous application of elicitors (abiotic or biotic) triggers a stress response by plants due to the perception of a mimicry of pathogen attack, which induces a concomitant enhancement in secondary metabolite production. Elicitor induced stress results in the activation of several defence-related genes or inactivation of non-defencerelated genes, transient protein phosphorylation/dephosphorylation, and expression of enzymes whose information can be used to ascertain the biosynthetic pathways of many secondary metabolites [22]. Furthermore, secondary metabolite pathways are very specific to the type of elicitor to which the cells are exposed, and there is variability in the mechanism of action entailing a wide range of metabolic responses to stress in plants. Based on our results we can affirm that the yeast extract applied is able to induce an increase of expression of the genes involved in anthocyanin biosynthesis and their accumulation. However, in the case of extreme climatic conditions, characterized by frequent heatwaves in which maximum temperatures can reach more than $40{ }^{\circ} \mathrm{C}$, the seasonal effect could prevail over the positive elicitation effect. In the light of our findings, it would be interesting to understand if in particularly warm years, a further application of LVM during veraison could counteract the climatic effect and even lead to an improvement in berry composition. 

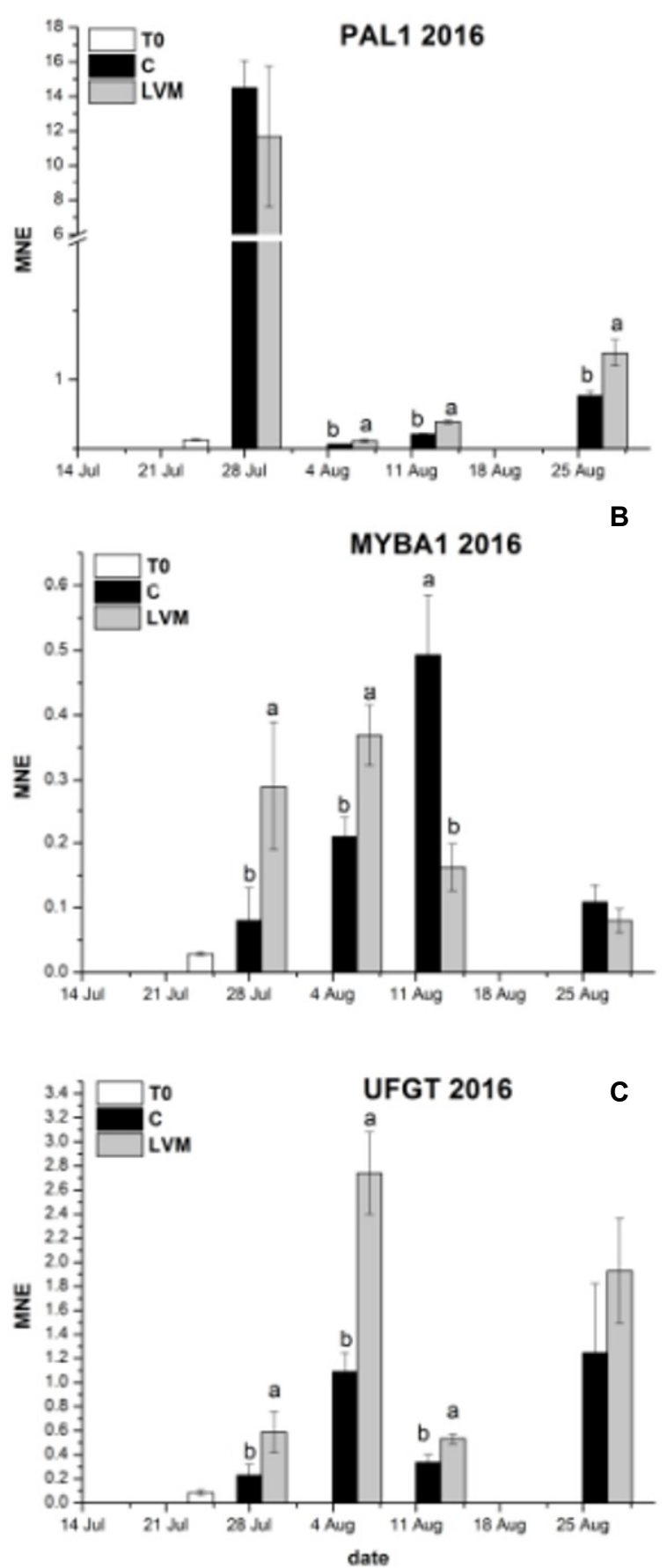
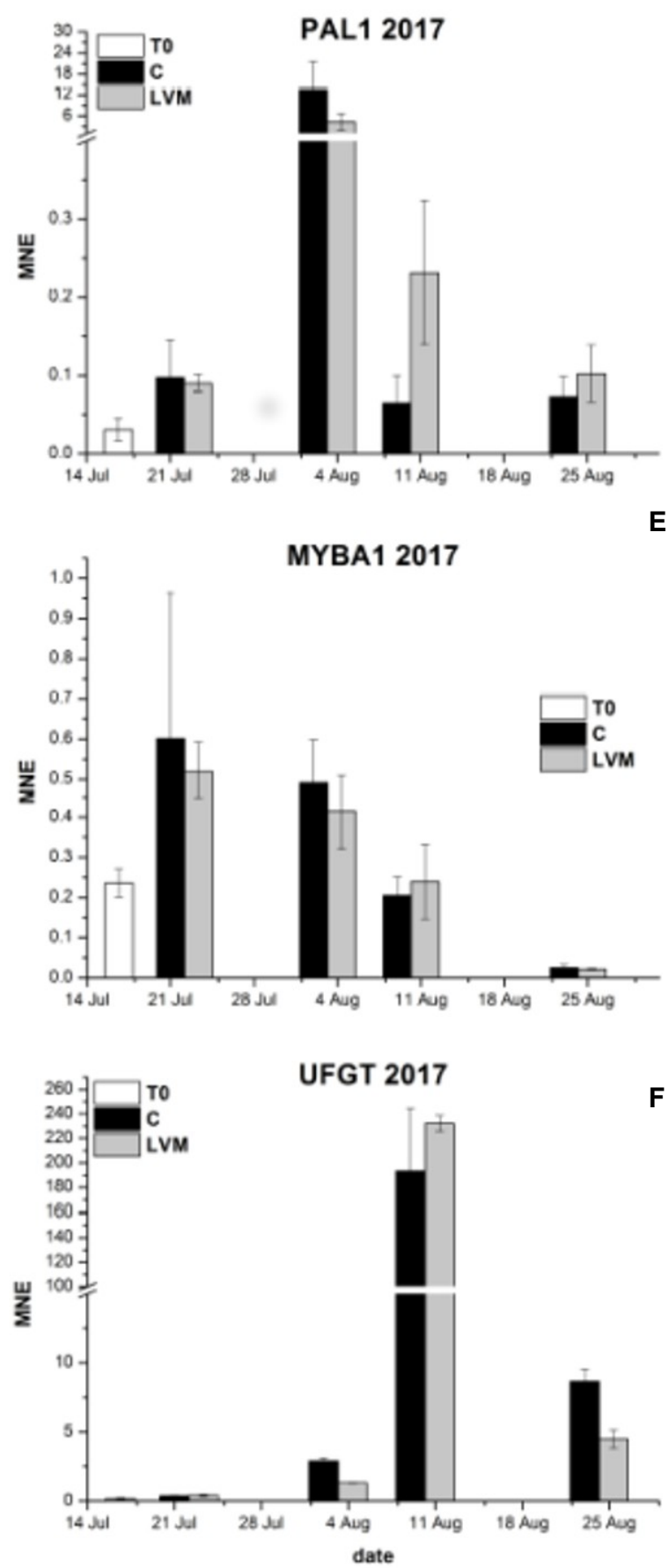

Fig 4. Gene expression analyses in C and LVM berries during 2016 (A-C) and 2017 (D-F) seasons. Error bars indicate standard error $(n=3)$. Means followed by different letters differ significantly, as calculated by Tukey statistical analysis $(\mathrm{p}<0.05)$.

\section{References}

1. N. Movahed, C. Pastore, A. Cellini, G. Allegro, G. Valentini, S. Zenoni, E. Cavallini, E. D'Incà, G. B. Tornielli, I. Filippetti. J. Plant Res. 129(3), 513526.(2016)

2. C. Pastore, S. Dal Santo, S. Zenoni, N. Movahed, G. Allegro, G. Valentini, I. Filippetti, G. B. Tornielli. . Front. Plant Sci. 8, 929 (2017).

3. Á. J. Luciano, T. P. Irineo, O. V. R. Virginia, A. A. Feregrino-Pérez, A. C. Hernández, G. G. R. Gerardo. Int. J. Agric. Biol. 19(3), 391-402 (2017)
4. J. Portu, P. Santamaria, I. Lopez-Alfaro, R. López, T. Garde-Cerdán, J. Agric. Food Chem. 63(8), 2328-2337 (2015)

5. J. Portu, R. López, E. Baroja, P. Santamaría, T. Garde-Cerdán, Food Chem. 201, 213-221, (2016)

6. E. Gómez-Plaza, A. B. Bautista-Ortín, Y. Ruiz-García, J. I. Fernández-Fernández, R. J. Gil-Muñoz, Sci. Food Agric. 97, 977-983 (2017).

7. S. Vitalini, A. Ruggiero, F. Rapparini, L. Neri, M. Tonni, M. Iriti. Food Chem. 162, 192-205 (2014). 
8. Y. Ruiz-García et al. 2014. Am. J. Enol. Vitic. 65, 238-243. DOI: 10.5344/ajev.2014.13119.

9. C. D'Onofrio, F. Matarese, A. Cuzzola, Food Chem. 242, 352-361 (2018)

10. S. Villangó, G. Pásti, M. Kállay, A. Leskó, I. Balga, A. Donkó, M. Ladányi, Z. Pálfi, Zsófi, Zs, S. Afr. J. Enol. Vitic. 36(3), 304-315 (2015)

11. S. Río Segade, S. Giacosa, M.A. Paissoni, C. Ossola, V. Gerbi, C. Suárez Martínez, F. Battista, J. Téllez Quemada, P. Vagnoli, L.Rolle. Macrowine 2016 Conference programme (2016)

12. B. Delaunois, G. Farace, P. Jeandet, C. Clément, F. Baillieul, S. Dorey, S. Cordelier, Environ. Sci. Pollut. R. 21(7), 4837-4846 (2014)

13. F. Mattivi, R. Guzzon, U. Vrhovsek, M. Stefanini, R. Velasco, J. Agr. Food Chem. 54(20), 7692-7702 (2006)

14. C. Pastore, S. Zenoni, G.B. Tornielli, G. Allegro, S. Dal Santo, G. Valentini, C. Intrieri, M. Pezzotti, I. Filippetti, BMC Genomics 12(1), 631 (2011)

15. J. Bogs, M.O. Downey, J.S. Harvey, A.R. Ashton, G.J. Tanner, S.P. Robinson, Plant Physiol. 139(2), 652-663 (2005)

16. A. Belhadj, N. Telef, C. Saigne, S. Cluzet, F. Barrieu, S. Hamdi, J.M. Mérillon, Plant Physiol. Bioch. 46(4), 493-499 (2008)

17. N. Goto-Yamamoto, G.H. Wan, K. Masaki, S. Kobayashi, Plant Sci. 162, 867-872 (2002)

18. S.T. Jeong, N. Goto-Yamamoto, S. Kobayashi, M. Esaka, Plant Sci. 167, 247-252 (2004)

19. P. Simon. 2003. Bioinformatics 19(11), 1439-1440.

20. F. Battista, A. Panighel, R. Flamini, D. Tomasi, L'informatore Agrario 22, 41-45 (2016).

21. D. Villegas, M. Handford, J.A. Alcalde, A. PerezDonoso, Plant Physiol. Bioch. 104, 125-133 (2016)

22. M. Narayani, S. Srivastava, Phytochem. Rev. 16(6), 1227-1252 (2017) 